Motrivivência $\quad$ v. $27, \quad$ n. $44, \quad$ p. $36-48$, maio/2015

http://dx.doi.org/10.5007/2175-8042.2015v27n44p36

\title{
CONHECIMENTOS ACADÊMICOS, SABERES E AFAZERES PEDAGÓGICOS DO PROFESSOR DE EDUCAÇÃO FíSICA: mapeando vínculos
}

Fernando Jaime González’ Robson Machado Borges ${ }^{2}$

\begin{abstract}
RESUMO
Esta investigação teve como objetivo identificar nos saberes mobilizados por uma professora de Educação Física em sua atuação docente, elementos de sua formação inicial. Para tanto, foi realizado um estudo de caso que consistiu na observação de dezessete aulas de uma professora, em uma escola de ljuí/RS. Os resultados indicam que grande parte dos saberes docentes manifestados pela docente, em sua atuação profissional, podem ser apontados como oriundos da formação inicial. Evidências disso podem ser constatadas observando a "pluralidade" das práticas corporais desenvolvidas e na forma de ensino dos esportes, pautada na tomada de decisão nos jogos de invasão, o que coincide com os princípios defendidos pelo curso de formação inicial que a docente frequentou.
\end{abstract}

Palavras-chave: Conhecimentos acadêmicos; Formação inicial; Atuação docente; Educação Física escolar

1 Doutor em Ciências do Movimento Humano, professor da Unijuí, ljuí, Rio Grande do Sul, Brasil.

E-mail: fjg@unijui.edu.br

2 Mestre em Ciências do Movimento Humano, professor da Unijuí, ljuí, Rio Grande do Sul, Brasil.

E-mail: robson.borges@unijui.edu.br 


\section{INTRODUÇÃO}

Este estudo faz parte do projeto "Educação Física e Cultura Escolar" desenvolvido por pesquisadores brasileiros em parcerias com professores de instituições estrangeiras. O referido projeto tem como principal objetivo estudar como a cultura escolar das instituições origina, afeta e estimula experiências bem-sucedidas, como também, o processo de abandono do trabaIho docente dos professores de Educação Física em instituições públicas de educação básica, em espaços geográficos distantes e contextos político-sociais diferentes.

No caso específico deste estudo, centra-se atenção nos "afazeres pedagógi$\cos ^{\prime \prime}$ do professor de Educação Física em seu cotidiano escolar. Acredita-se que a função desse profissional, a partir das oportunidades que a disciplina permite oferecer aos alunos na educação básica, é complexa e está atravessada por um universo de possibilidades. Acorda-se que está na conta da Educação Física, enquanto componente curricular nas escolas, "tratar das possibilidades de movimento dos sujeitos, representações e práticas sociais que constituem a cultura corporal de movimento, estruturadas em diversos contextos históricos e, de algum modo, vinculadas ao campo do lazer e da saúde" (GONZÁLEZ; FRAGA, 2012, p. 43). Tal compreensão leva-nos a refletir sobre a amplitude de saberes que um docente pode mobilizar durante sua função republicana de educador ${ }^{3}$, para desenvolver uma série de assuntos, tais como: a) definir uma estrutura curricular, optando/selecionando quais práticas corporais sistematizadas irá trabalhar; b) determinar uma estrutura curricular, definindo quais representações sociais serão abordadas; c) escolher entre os conhecimentos - conceitual, procedimental e atitudinal -, qual(is) será(ão) privilegiado(s) em determinado assunto; d) desenvolver suas aulas pautadas em uma metodologia de ensino coerente com os propósitos intencionados; e) selecionar quais tarefas serão utilizadas de acordo com o objetivo da aula; f) atentar para a forma de participação dos alunos nas atividades; g) definir sua maneira de intervenção junto aos alunos. Logicamente, entendemos que para constituir saberes sobre os assuntos apontados, o professor - em algum momento - precisa ser oportunizado a tal, e nesse processo, pensamos que a formação inicial tem uma função essencial.

$\mathrm{Na}$ contemporaneidade, para concluir o ensino superior em Educação Física, o indivíduo dedica um considerável tempo de sua vida nos bancos universitários. Mesmo assim, temos visto alguns autores apontar que grande parte dos professores tem imensa dificuldade no que se refere ao desenvolvimento de aulas na Educação Física escolar, que possibilitem ao aluno uma apropriação efetiva do conhecimento, por exemplo, em relação ao ensino dos esportes (GARGANTA, 1998; GRAÇA, 1999; GAYA, 2000).

Este contexto nos remete a pensar sobre o real aprendizado dos acadêmicos durante a formação inicial e, consequentemente, sobre a origem dos saberes que o docente de Educação Física mobiliza

3 González e Fensterseifer (2009) compreendem que a Educação Física, enquanto componente curricular, é responsável por um conhecimento específico que está subordinado a funções sociais da escola republicana, em uma sociedade democrática. 
durante as aulas na escola. Esses saberes são construídos ao longo da vida dos educadores (TARDIF, 2002), com experiências relacionadas ao meio em que esteve (ou está) inserido, como, por exemplo, no caso do professor de Educação Física: a) ter sido um praticante de uma ou outra manifestação da cultura corporal de movimento; b) suas experiências como aluno no ensino básico; c) os primeiros anos de exercício profissional; d) a formação continuada. Assim, esta pesquisa teve como centralidade investigar como os conhecimentos construídos na formação inicial podem ser mobilizados no cotidiano escolar, tanto na sua forma explícita - conteúdos declarados no programa de estudos -; quanto implícita - conhecimentos transmitidos de maneira não formal: compromisso profissional e valores de cidadania e desenvolvimento humano como a cooperação, o respeito, a inclusão, a socialização, entre outros.

Tendo o contexto apresentado como preocupação, desenvolvemos uma investigação orientada pela seguinte questão: os saberes docentes mobilizados por uma professora de Educação Física em sua atuação profissional no ensino fundamental podem ser apontados como elementos de sua formação inicial?

\section{O processo de mobilização de saberes do professor de Educação Física e a Formação Inicial}

Ao pesquisar o mundo da intervenção profissional no trabalho de professores, julgamos pertinente compreender os saberes docentes. Para Tardif (2002), eles englobam os conhecimentos, as competências, as habilidades e as atividades dos educadores. Esses saberes são oriundos da formação inicial e continuada dos professores, do currículo e da socialização escolar, do conhecimento das disciplinas a serem ensinadas, da experiência na profissão, da cultura pessoal e profissional e da aprendizagem com os pares. Para Townsend e Tomazzeti (2007) os saberes têm procedência da história de vida dos professores, da formação profissional e da prática que o educador realiza.

A construção dos saberes docentes acontece através de um aprendizado progressivo, não é algo que se define em um determinado momento da vida. Consequentemente, pode ser alterada durante a trajetória profissional. Assim, um professor pode ter um saber sobre um assunto em um momento, e passado algum tempo dependendo de acontecimentos ocorridos - poderá ter um saber diferente do que tinha anteriormente sobre o mesmo assunto.

Para Tardif (2002), os saberes dos professores são saberes sociais. O autor faz essa afirmativa através de cinco colocações: a) porque são compartilhados por todo um grupo de educadores que possuem uma formação comum e trabalham em uma mesma organização; b) porque sua posse e utilização repousam sobre todo um sistema que vem garantir sua legitimidade; c) porque seus próprios objetos são objetos sociais; d) pelo fato de $o$ que os professores ensinam e a maneira como ensinam evoluem com o tempo e com as mudanças sociais; e) por serem adquiridos no contexto de uma "socialização profissional", sendo mudados/adaptados em função da fase da carreira do docente.

Nesse sentido, tendo os saberes como sociais parece claro que os próprios saberes profissionais dos professores não são definidos unicamente por eles. Ademais, a constituição do saber é fruto de acontecimentos ocorridos na sociedade e nos mais diversos grupos. 
Essa questão social relacionada aos saberes, está interligada também, ao conhecimento dos professores, pois:

o que um professor sabe depende também daquilo que ele não sabe, daquilo que se supõe que ele não saiba, daquilo que os outros sabem em seu lugar e em seu nome, dos saberes que os outros the opõem ou the atribuem... Isso significa que nos ofícios e profissões não existe conhecimento sem reconhecimento social (TARDIF, 2002, p. 13).

Em linhas gerais, pode-se afirmar que os professores de Educação Física, por um lado, compartilham saberes comuns com os profissionais da educação de outras áreas e, por outro, necessitam de saberes específicos vinculados tanto aos conteúdos particulares do componente curricular, como também a administração da disciplina no contexto escolar.

No grupo de saberes comuns a outras áreas, podem ser mencionados: a importância de dominar os assuntos relacionados à sua área de atuação, utilizar instrumentos tecnológicos para diversificar as aulas, trabalhar com alunos que apresentam diferentes problemas de aprendizagem, motivar os discentes para realização das atividades, entre outros.

No grupo de conhecimentos específicos, um professor mobiliza durante seu trabalho saberes para tratar de práticas corporais sistematizadas que são próprias do componente curricular, como: a dança, os esportes, a ginástica, as lutas, as práticas corporais junto à natureza, entre outros. Para Gallardo (2003), o professor de Educação
Física deve utilizar saberes que o ajude a ser capaz de analisar, compreender, descrever e sistematizar diferentes atividades da cultura corporal e desenvolver esses conhecimentos no cotidiano profissional. Ainda, de acordo com Betti e Zuliani (2002, p. 75), os saberes específicos dos docentes devem buscar "auxiliar o aluno a compreender o seu sentir e o seu relacionar-se na esfera da cultura corporal de movimento". Isto é, não lidar apenas com conteúdos procedimentais e conceituais, mas também com a sensibilidade, as atitudes e os valores para consigo e para com os outros.

Para ter condições de desenvolver diferentes temas de ensino durante o período de Graduação, os acadêmicos do curso de Educação Física têm a oportunidade de estudar uma série de componentes curriculares, que são ministrados por diferentes professores. Esse processo faz com que os graduandos possam adquirir diversos saberes durante o curso de formação inicial. Logo, espera-se que os saberes adquiridos durante a Graduação, sejam mobilizados pelos docentes em suas aulas, ainda, que diferentes estudos tenham mostrado que os conhecimentos mobilizados na docência, não são apenas procedentes da formação inicial (TARDIF, 2002).

\section{PROCEDIMENTOS METODOLÓGICOS}

Essa investigação se caracteriza como um estudo de caso, que utilizou como fonte de análise a atuação docente da professora de Educação Física Joana ${ }^{4}$, a

4 Para preservar a identidade da participante desta investigação, o nome apresentado é fictício. 
qual atuava nas séries finais do ensino fundamental, em uma escola da rede pública de ensino do município de ljuí/RS. Essa docente de 31 anos de idade concluiu o curso de Graduação em 1999 e Pós-Graduação Especialização em Educação Física escolar, em 2005, pela Unijuí - Universidade Regional do Noroeste do Estado do Rio Grande do Sul. O critério de escolha da docente para participar da pesquisa, deveu-se ao fato de a mesma fazer parte de um conjunto de professores da região que realizam práticas inovadoras em Educação Física, em que foi estudado pelo projeto maior com o qual se articula essa investigação.

Os instrumentos utilizados na coleta dos dados foram:

- observações das práticas desenvolvidas - tanto em sala de aula, como em espaços abertos ${ }^{5}$ - durante o período de agosto a dezembro de 2008;

- diário de campo, no qual foram registrados as atitudes, os comportamentos e as falas da professora, alunos e membros da comunidade escolar, que interatuavam com ela, antes, durante e após as aulas;

- entrevista semiestruturada para ajudar a verificar o objetivo dessa investigação;

- questionário com questões objetivas, visando identificar aspectos relacionados à atuação da professora - como tempo de docência e formação, por exemplo.
A respeito dos procedimentos éticos da pesquisa, a professora aceitou participar do estudo e autorizou a divulgação dos resultados, através da assinatura do Termo de Consentimento Livre e Esclarecido. Nesse documento, consta que a participação foi voluntária, ou seja, a docente teve a opção de escolher se desejava, ou não, participar. Mesmo após confirmar participação, a professora poderia desistir de participar, em qualquer momento da pesquisa, sem sofrer qualquer tipo de sanção ou ser prejudicada.

Na mesma linha, a investigação obedeceu à legislação vigente, no que diz respeito às pesquisas que envolvem seres humanos. Sendo assim, ocorreu a preservação da identidade da educadora. Cabe ressaltar que a professora participante teve acesso à leitura da pesquisa e concordou com todas as falas e informações referidas a ela.

As observações das aulas aconteceram em um total de dezessete, nove na turma da sétima série e oito na turma da oitava série do ensino fundamental da escola onde a professora trabalhava. Essas turmas tinham horário de aula nas quintas-feiras, sendo que a sétima série tinha aula das 7h30min às $9 \mathrm{~h} 30 \mathrm{~min}$ e a oitava série das $9 \mathrm{~h} 30 \mathrm{~min}$ às $11 \mathrm{~h} 30 \mathrm{~min}$. Nessa parte do estudo, como não é possível descrever os acontecimentos das dezessete observações, apresentamos a descrição de nove aulas ministradas pela professora, cinco na turma da sétima (observações 1, 5, 7, 9 e 13) e quatro na turma da oitava série (observações 2, 8, 10 e 16) ${ }^{6}$,

5 Quadra de esportes, academia de ginástica, academia de musculação, entre outros.

6 Visando facilitar a compreensão, apresentamos as observações de forma consecutiva da sétima e, posteriormente, da turma da oitava série. 
escolhidas por destoarem dos conteúdos tradicionais da Educação Física escolar? Após, segue o relato de algumas atitudes e comportamentos da docente no seu papel de educadora.

A primeira observação das aulas da professora Joana, ocorreu na turma da sétima série, composta na época por vinte e três alunos. Nessa oportunidade, a docente ministrou uma aula teórica sobre: os conceitos de atividade física, exercício físico, aptidão física e o "funcionamento" de alguns músculos, ossos e órgãos do corpo humano.

Metodologicamente, a professora utilizou um caderno para transmitir os conteúdos aos alunos, ou seja, as informações que escrevia no quadro eram copiadas do caderno que carregava consigo. Ainda, para facilitar a compreensão dos conteúdos por parte dos alunos, ela utilizou desenhos no quadro. Na parte final da aula explicou o "dever de casa", o qual consistia em uma pesquisa, em duplas, sobre alguns grupos musculares - nomenclatura, localização, função, inserção - para apresentar aos colegas na próxima aula.

A interação pedagógica com os alunos aconteceu de forma tranquila, pois os alunos respeitavam a professora e demonstravam interesse pelo que estava sendo ensinado. Isso, por consequência, resultava em uma excelente relação professora-aluno.

Na quinta observação que realizamos - terceira na turma da sétima série - a professora aplicou uma avaliação escrita, composta de vinte questões, com os conteúdos mencionados na primeira observação, além de questões relacionadas à modalidade esportiva voleibol, que havia sido trabalhada anteriormente ao início das observações. Nesse dia, após entregar as avaliações, a docente procedeu metodologicamente lendo cada uma das vinte questões, ao mesmo tempo em que esclarecia algumas perguntas surgidas durante a leitura. Enquanto os alunos realizavam a avaliação, ela corrigiu alguns trabalhos e também acompanhou os educandos sanando, em voz alta para toda turma, as dúvidas relacionadas às questões da avaliação.

Ao ser questionada sobre o motivo da proposição de uma avaliação escrita aos alunos, a docente apontou: "Acho que esta é uma excelente forma de avaliar o desempenho dos alunos. A prova escrita faz com que os alunos e a direção percebam que a Educação Física tem uma série de conteúdos a serem desenvolvidos, assim como as outras disciplinas".

Em relação aos questionamentos realizados à docente, sobre algumas intervenções, como ler todas as questões para os alunos e sanar dúvidas em voz alta para toda a turma, percebemos que ela visava uma melhor compreensão/aprendizagem e relacionava essas ações com as quais vivenciou durante sua formação profissional: "Às vezes os alunos não acertam uma questão porque não entendem o enunciado. Não me interessa eles irem mal na prova, eu quero que eles aprendam. Lembro que poucos professores [durante a formação profissional] explicavam claramente para toda turma o que se estava perguntando".

7 Optamos por esse critério para selecionar as descrições das aulas, por entender que o mesmo tem relação com o objetivo deste estudo, à medida que a universidade em que a docente realizou a formação inicial defende a pluralidade de temas de ensino na Educação Física escolar. 
Na sétima observação - quarta na turma da sétima série -, Joana começou a aula devolvendo as provas aos alunos. Como a maioria deles teve um baixo aproveitamento, a aula que seria sobre basquetebol, acabou tendo três momentos distintos: no primeiro, a educadora realizou a correção da avaliação com os alunos; no segundo, aconteceu uma aula teórica sobre o basquetebol, centrada na classificação desse esporte ${ }^{8}$; e, em um terceiro momento, a professora levou os alunos à quadra, onde realizou uma parte prática da modalidade mencionada.

Na parte prática, os conteúdos desenvolvidos foram as intenções táticas: "desmarcar-se para receber a bola" e "arremessar quando estiver em condições favoráveis". Os procedimentos metodológicos consistiram em realizar um alongamento, seguido de um aquecimento com um jogo reduzido. Durante essa atividade, seguidamente a professora realizava intervenções relacionadas ao conteúdo de ensino proposto. Eis duas elocuções da docente registradas no diário de campo: "Aparece! Quem aparece para receber a bola?"; "Arremessa Diego, você está livre... arremessa!".

Ao analisar essa aula constatamos que durante a parte teórica, a professora desenvolveu os conteúdos relacionados ao conhecimento conceitual. Já na parte prática, a centralidade do trabalho esteve voltada aos conhecimentos procedimentais sobre o basquetebol, mais precisamente, em uma forma alternativa de pensar o ensino dos esportes, tendo a tomada de decisão como lógica central de atuação no jogo.

Julgamos pertinente registrar que essa forma de proceder no ensino dos esportes, faz parte da orientação do curso de formação profissional que a professora concluiu, como podemos perceber através da seguinte fala: "Aqui na Unijuí, com a chegada do Ricardo ${ }^{9}$, a gente tem essa vantagem de aprender a ensinar o esporte fazendo o aluno pensar e não só a executar movimentos". Isso contrasta com a forma que ela aprendeu os esportes, enquanto aluna do ensino básico: "Eu fui aprender que tomar decisões no jogo é importante, que têm jogadas, estratégias, posicionamentos... na faculdade. Nas aulas [no ensino básico] o professor que tive colocava a gente pra jogar e pra correr, quando não era isso, era abdominal [...]".

Na nona observação das aulas quinta na turma da sétima série -, foram desenvolvidos os conteúdos de ensino: a origem dos esportes ${ }^{10}$, as regras do basquetebol e duas intenções táticas. Na sala de aula, Joana trabalhou com os conteúdos em uma perspectiva conceitual. Na explicação sobre as regras do basquetebol, ela utilizou uma bola para facilitar a compreensão dos alunos a respeito: da reposição de bola em jogo/como jogar a bola, do empate e tempo extra, do lance livre e dos tempos de 3, 5, 8 e 24 segundos.

8 A docente utilizou a classificação dos esportes proposta por González (2006), que aprendeu durante a formação inicial.

9 Nome fictício para fazer referência a um professor do curso de Educação Física da Unijuí, que trabalha com disciplinas relacionadas ao ensino dos esportes.

10 No sentido de que os esportes não "nasceram" esportes, e sim, eram jogos que se tornaram esportes em consequência de fatores culturais. 
Na sequência, a docente levou os alunos à quadra para a parte prática de basquetebol, a qual foi iniciada com uma tarefa chamada "sempre 2, nunca $3^{\prime \prime 11}$. Passados cerca de dez minutos, a professora mudou a ordem da atividade ${ }^{12}$ e, após, realizou um alongamento. Para o desenvolvimento do conteúdo, os alunos foram divididos em quatro equipes ( $A, B, C$ e D) que, tendo a quadra "dividida" em dois setores, jogaram em um lado as equipes " $A$ " $e$ " $B$ " e no outro as equipes " $C$ " e " $D$ ", em um jogo semeIhante ao basquetebol. Durante o jogo, a docente realizou algumas explicações sobre as intenções táticas "observar antes de agir" e "arremessar quando estiver em condições favoráveis". Eis algumas orientações da professora: "Vocês botam a bola fora, dão de graça... tem que prestar atenção antes de passar"; "[...] gente, quando vocês pegarem a bola e não tiver ninguém na frente de vocês, vão pra cesta".

Na décima terceira observação que realizamos - sétima na turma da sétima série -, a docente propôs uma reflexão sobre diferentes tipos de preconceitos: racial, físico, formas de falar, entre outros. Durante esse processo, a educadora questionou os alunos: "Quais os tipos de preconceitos que apareciam no filme? ${ }^{13}$ Quais os tipos de preconceitos existentes na sociedade? Alguém na sala já sofreu algum tipo de preconceito? Alguém na sala já foi preconceituoso com alguém?".
Posteriormente, a professora inseriu nas reflexões o tema "deficiência visual". $\mathrm{Na}$ tentativa de fazer com que os alunos entendessem a dificuldade do referido assunto, a docente realizou três atividades: a) com os olhos fechados, os alunos pegaram pequenas caixas de papel, nas quais havia palavras em braile; b) em duplas, um aluno - através de falas - deveria conduzir o outro, que estava com os olhos vendados, objetivando pegar uma revista que estava em outra sala; c) também em duplas, um aluno deveria interpretar um indivíduo que só conseguia mexer a cabeça e o outro educando da dupla teria que representar uma pessoa que mexia apenas um dos braços. A missão das duplas foi fazer com que cada um conseguisse comer/chupar uma bala que estava a sua frente, respeitando as limitações de movimentos. Terminado a atividade, a educadora solicitou aos alunos que respondessem em uma folha do caderno - essa folha deveria ser entregue - três questões: 1) O que você sentiu durante as atividades? 2) O que foi mais difícil de fazer e por quê? 3) Pensando na aula de hoje, você pode mudar suas atividades em relação às diferenças que cada um de nós possui? Como?

Durante essa aula, a professora atuou como mediadora nas discussões sobre o tema preconceito, instigando os alunos a participar do debate. Essa função de mediar conhecimentos foi identificada

11 Nesta atividade os alunos são dispostos em um círculo. Um aluno (quicando um bola) deverá fugir de outro aluno que tentará pegá-lo (esse também estará quicando uma bola). Quando o aluno que está fugindo passa a bola para outro colega que está no círculo, esses dois alunos trocam de papéis, ou seja, quem recebeu a bola irá fugir e quem passou ficará parado no círculo.

12 Agora, quem recebe a bola passa a ser o pegador e quem passou ficará parado no círculo.

13 A docente fez referência ao filme "Estrada Para Glória", que abordava o preconceito racial e havia sido assistido na aula anterior. 
pela educadora em seus professores durante a formação inicial: "[...] tinha um ou outro professor na faculdade que ficava intermediando as discussões, fazendo tipo um debate interessante na sala".

A primeira observação das aulas da professora Joana na turma da oitava série segunda no geral - aconteceu no dia vinte e oito de agosto. Para essa turma, composta por oito alunos, a docente desenvolveu uma aula teórica, na qual tematizou os conceitos de IMC (índice de massa corporal), RCQ (relação cintura quadril) e resistências aeróbia e anaeróbia. Metodologicamente, as ações da docente foram idênticas às mencionadas na primeira observação realizada na turma da sétima série. Novamente, chamou-nos a atenção o excelente relacionamento da professora com os alunos. Percebemos que os discentes identificavam um "conhecimento" e um valor profissional na educadora.

Na quarta observação da atuação docente da professora na turma da oitava série - oitava no geral -, ela levou os alunos a uma academia da cidade ${ }^{14}$, onde os mesmos tiveram uma aula sobre os seguintes conteúdos: musculação, step e aero jump. Metodologicamente, a professora explicou o funcionamento de uma aula de aero jump e, após, ministrou uma aula de step $^{15}$ para os alunos. Posteriormente, ela demonstrou o funcionamento, a nomenclatura e a utilização dos aparelhos de musculação. Logo, os alunos vivenciaram corporalmente os exercícios nos aparelhos, enquanto a professora corrigia questões relacionadas à postura corporal.

Acreditamos que se faz pertinente o registro do fato de que antes de se deslocar à academia, ainda na escola, a professora advertiu os alunos sobre o comportamento que deveriam ter "na visita"16, falando o seguinte: "Pessoal, vocês sabem o trabalho que deu conseguir levar vocês lá, então se comportem como vocês sempre fizeram".

A quinta aula observada na oitava série - décima no geral - teve como conteúdo o exercício físico step. Inicialmente, a educadora realizou uma aula teórica, desenvolvendo o conhecimento conceitual sobre o conteúdo e, posteriormente, em uma aula prática, trabalhou com os alunos o conhecimento procedimental de alguns passos básicos ${ }^{17}$. Ao final da aula, a professora solicitou um trabalho aos alunos, orientando-os a montar uma coreografia de no mínimo oito movimentos, sendo que três desses deveriam ser criados por eles.

Como processos de interação pedagógica acontecidos na aula, observamos que a professora "chamou" a atenção de uma aluna que estava subindo e descendo do step com os braços cruzados e, dos alunos em geral, para realizarem os passos no ritmo da música. Após o término da aula de step, a docente falou que o objetivo não era fazer com que os alunos aprendessem a dar uma aula de step, mas sim, que tivessem uma vivência naquela prática corporal.

14 A professora e os alunos utilizaram ônibus - transporte coletivo da cidade - como meio de locomoção à academia de musculação.

15 Essa aula teve duração de 15 minutos.

16 Termo utilizado pela professora.

17 "Chute lateral", "L", "4", "sobe e desce" e "elevação de joelho". 
Na última observação das aulas da professora Joana na oitava série - décima sexta no geral -, ela levou os alunos para vivenciarem a prática do rapel ${ }^{18} \mathrm{em}$ um local na cidade de ljuí, onde um professor de Educação Física ${ }^{19}$ desenvolve essa atividade. Nessa aula, o profissional realizou uma fala explicando como realizar o rapel e na sequência os alunos vivenciaram a técnica de descida por várias vezes. Durante a prática, a professora realizou a segurança ${ }^{20}$ dos alunos.

Em meio aos ensinamentos do profissional mencionado, a educadora realizou falas e orientações aos alunos sobre o tema de ensino daquela manhã, particularmente, em questões de segurança: "Essa é uma corda especial, a prática do rapel não pode ser feita com qualquer corda".

Após as dezessete observações das aulas, acompanhamos a professora Joana durante a correção das avaliações escritas, realizadas pelos alunos da sétima e da oitava séries. Nessa oportunidade, identificamos - através das respostas da professora aos nossos questionamentos - que a docente: a) valoriza a ideia do aluno. Eis uma fala que aponta isto: "não precisa ser exatamente a resposta correta, com todas as letras, basta o aluno mostrar que entendeu alguma coisa sobre a questão"; b) considera a questão como "certa", mesmo quando a essa não estava totalmente correta.
Importante apontar que o fato de a docente propor avaliações escritas aos alunos, não é um acontecimento comum na atuação docente dos professores de Educação Física (González; Fraga, 2012). De acordo com declarações da educadora, seu objetivo não era atribuir "notas" aos alunos e sim, verificar o aprendizado dos mesmos, como acontece em outros componentes curriculares. Ainda, a professora utiliza esse processo como forma de reflexão sobre o seu desempenho profissional.

Ao analisar o procedimento avaliativo utilizado pela docente, percebemos que há semelhança com a metodologia avaliativa vivenciada pela educadora durante sua formação inicial. Pois, alguns professores que ela teve durante a graduação incentivaram a utilização de prova escrita como ferramenta de avaliação dos alunos: "Na faculdade tive professores que incentivavam a utilização da avaliação escrita... [...] acho muito interessante, pois os alunos se obrigam a estudar e aprender".

\section{ANÁLISE DOS DADOS E DISCUSSÃO DOS RESULTADOS}

O produto dessa investigação aponta indicativos de que a professora observada mobilizava, em sua atuação profissional, uma série de saberes docentes oriundos da formação inicial ${ }^{21}$. Essa afirmação está

18 A professora e os alunos utilizaram ônibus - transporte coletivo da cidade - como meio de locomoção até o local da prática.

19 Esse profissional é amigo da professora e realizou esse trabalho gratuitamente.

20 Na prática do rapel, uma pessoa fica do solo segurando a corda, pronta para firmá-la, em caso de "problemas" com o indivíduo que estiver descendo.

21 Durante a análise dos dados, além dos materiais utilizados na coleta das informações, usamos como referência a grade curricular do curso de Graduação de Educação Física que a professora frequentou e o conhecimento de um dos pesquisadores - que foi acadêmico do mesmo curso e na mesma universidade - sobre a atuação de docentes que foram professores da Joana durante a graduação. 
baseada principalmente na análise: a) da pluralidade dos temas/conteúdos propostos; b) do desenvolvimento de conteúdos conceituais; c) da metodologia utilizada no ensino dos esportes.

Ao analisar os temas/conteúdos de ensino propostos por Joana, identificamos a existência de um princípio de "pluralidade", os quais não ficam reduzidos às modalidades esportivas. Conforme mencionado nas observações das aulas, a docente abordava temas incomuns nas aulas de Educação Física escolar, tais como: atividades físico-esportivas com a natureza, o funcionamento do corpo humano, exercícios físicos em academias, entre outros. Esse processo coincide com os princípios defendidos pelo curso de formação inicial que a docente frequentou. Ao ser questionada sobre o porquê trabalhar com diversos temas de ensino, a professora respondeu: "[...] os professores que tive na escola não ensinavam nada diferente e na faculdade a gente estuda aquele monte de coisas... Eu acho que dentro da cultura corporal de movimento do aluno, a gente tem que proporcionar o máximo de vivências para os alunos". Essa ideia de diversidade de temas de ensino é defendida por González e Fraga (2012), à medida que os autores defendem a amplitude dos assuntos compreendidos na cultura corporal de movimento, como um direito de aprendizado que precisa ser garantido ao discente. $\mathrm{Na}$ mesma linha, Gallardo (2003) compreende que cabe ao docente de Educação Física utilizar saberes que o permitam desenvolver diferentes atividades da cultura corporal no cotidiano profissional.

Outra análise possível refere-se ao fato de a docente realizar o desenvolvimento do conhecimento conceitual dos conteúdos. Esse procedimento metodológico, além de não ser comum na Educação Física escolar (GONZÁLEZ; FRAGA, 2012), é semelhante à forma estudada pela professora durante a formação inicial, em que o saber sobre é bastante trabalhado. Por outro lado, diferencia-se da experiência que teve como aluna no ensino básico, no qual as aulas de Educação Física eram desenvolvidas na perspectiva técnica de apenas um tema de ensino: o esporte. Nesse sentido, parece-nos que o entendimento de que a formação inicial constitui uma importante fase de aquisição de saberes (TARDIF, 2002; TOWNSEND; TOMAZZETI, 2007) se confirma nesse caso.

Ao analisar as observações da atuação da professora em relação à metodologia utilizada no ensino dos esportes, é possível identificar um trabalho sobre a ótica de um modelo de ensino alternativo, orientado à tática, tendo o esporte como um processo permanente de resolução dos problemas surgidos a partir da situação de jogo. Segundo Gonzalez e Fraga (2012), esse modo de ensino se constitui eficaz por centrar atenção na tática individual, utilizar prioritariamente tarefas que proporcionem interação entre adversários, proporcionando um papel ativo/protagonista aos alunos. Essa forma de pensar e ensinar os esportes foi aprendida pela docente na formação inicial. A referida proposta do curso de Educação Física - com suas contradições - é alternativa à tradição docente na área e, dessa forma, a professora encontrou sustentação suficiente para empenhar-se e conseguir um ensino diferenciado.

\section{CONCLUSÕES}

O processo de tentativa de identificação de vínculos entre os saberes adquiridos na formação inicial e os saberes 
docentes mobilizados pelos professores na atuação profissional é um processo intrincado. Pois, os saberes podem ser oriundos de muitas fontes e constituídos em distintos momentos da vida (TARDIF, 2002).

Nesse contexto, levando em consideração os limites dessa investigação, acreditamos que grande parte dos saberes docentes manifestados pela professora, e mencionados na análise dos dados, podem ser apontados como oriundos da formação inicial. Porém, sem negar possíveis influências de outras fontes como a formação continuada, por exemplo.

Desse modo, para que a grande parte dos professores consiga trabalhar com temas variados e, consequentemente, proporcionem um vasto campo de conhecimentos e vivências aos alunos, a formação inicial deve proporcionar saberes relacionados aos diversos eixos de ensino que a Educação Física abrange. Não obstante, é preciso que o professor mobilize esses conhecimentos acadêmicos durante sua atuação profissional.

Sendo assim, a formação inicial parece ser importante para a atuação profissional, entretanto, nem todas as pessoas que passam pela mesma formação utilizam/ mobilizam os mesmos conhecimentos. Nesse sentido, torna-se necessário empreender novas investigações para descobrir quais disposições levaram/permitiram a professora Joana construir conhecimentos relevantes para sua atuação profissional durante a graduação, enquanto outros colegas que passaram pelas mesmas experiências de formação profissional, não foram sensibilizados por essas.

\section{REFERÊNCIAS}

BETTI, M.; ZULIANI, L. R. Educação Física escolar: uma proposta de diretrizes pedagógicas. Revista Mackenzie de Educação Física e Esporte, São Paulo, v. 1, n. 1, p. 73-81, jan/dez. 2002.

GALLARDO, J. S. P. Delimitando os conteúdos da cultura corporal que correspondem à área de Educação Física. Conexões, Campinas, v. 1, n. 1, p. 34-54, 2003.

GARGANTA, J. Para uma teoria dos jogos desportivos coletivos. In: GRAÇA, A.; OLIVEIRA, J. O Ensino dos jogos desportivos. Porto: Rainho \& Neves, 1998.

GAYA, A. Sobre o Esporte para Crianças e Jovens. Movimento, v. 7, n. 13, dezembro, 2000, pp. I-XIV.

GONZÁLEZ, F. J. FRAGA, A. B. Afazeres da Educação Física na escola: planejar, ensinar, partilhar. Erechim: Edelbra, 2012.

GONZÁLEZ, F. J. Sistema de classificação dos esportes. In: REZER, R. (Org.). O fenômeno esportivo. Chapecó: Argos, 2006, p. 111-120.

GRAÇA, A. Conhecimento do professor de Educação Física. In: BENTO, J. O.; GARCIA, R. Contextos da pedagogia do desporto: perspectivas e problemáticas. Livros Horizontes, 1999.

RANGEL-BETTI, I. C. Educação Física escolar: olhares sobre o tempo. Motriz. v. 5, n.1, p. 37-39, jun. 1999.

TARDIF, M. Saberes docentes e formação profissional. Petrópolis: Ed. Vozes, 2002.

TOWNSEND, C. B.; TOMAZZETI, E. M. A mobilização de saberes nas práticas de professores nos anos iniciais: um estudo de caso. Educar em revista, Curitiba: n. 29, p. 207-221, jan/jun, 2007. 
ACADEMIC SKILLS, KNOWLEDGE PEDAGOGIC TASKS OF THE PHYSICAL EDUCATION TEACHER: mapping links

\begin{abstract}
This research had to identify the knowledge mobilized by a physical education teacher in her teaching practice evidences of her initial formation. Therefore, we performed a study case consisted of seventeen lessons in observation of a teacher, in school in ljuí/RS. The results indicate most of the part of the knowledge manifested by the teacher in her professional practice, can be identified as original from the initial formation. Evidences of this can be found by looking the plurality of bodily practices developed and in the form of education and sports, based on the decision making in the invasion games, which coincides with the principles defended by course of initial formation the teacher.
\end{abstract}

Keywords: Academics skills; Initial formation; Teaching practice; School Physical Education

\title{
CONOCIMIENTOS ACADÉMICOS, SABERES Y PRÁCTICAS PEDAGÓGICAS DEL PROFESOR DE EDUCACIÓN FÍSICA: mapeando vínculos
}

\section{RESUMEN}

Esta investigación buscó identificar en los saberes movilizados por una profesora de educación física en su práctica docente, elementos de su formación inicial. Con ese propósito, se realizó un estudio de caso que consistió en la observación de diecisiete clases de una profesora que trabajaba en una escuela pública de la ciudad de ljuí/RS. Los resultados indican que la mayor parte de los saberes docentes activados por la profesora en su práctica profesional, pueden ser identificados como procedentes de su formación inicial. Es evidencia de eso, la "pluralidad" de prácticas corporales tematizadas y la centralidad dada a la tomada de decisión cuando enseña los deportes de invasión, aspectos que coinciden con principios defendidos por la institución en que la profesora cursó su formación inicial.

Palabras clave: Conocimientos académicos; Formación inicial; Actuación docente; Educación Física Escolar

Recebido em: setembro/2014

Aprovado em: dezembro/2014 